\title{
A Clinico-Pathological Correlation Study of Leprosy in a Tertiary Care Teaching Institute in Northwest Punjab, India
}

\author{
Raveneet Badhan $^{1}$, Ramesh Kumar Kundal ${ }^{1}$, Rakesh Tilak Raj, ${ }^{2, *}$, Rakesh Kumar Bahl ${ }^{2}$, Manjeet Singh Bal ${ }^{1}$ \\ ${ }^{1}$ Department of Pathology, Government Medical College, Patiala (Punjab), India \\ ${ }^{2}$ Department of Dermatology, Venereology and Leprosy, Government Medical College, Patiala (Punjab), India \\ *Corresponding author: rakeshtraj2012 @gmail.com
}

Received July 16, 2014; Revised October 21, 2014; Accepted October 22, 2014

\begin{abstract}
Background: Leprosy continues to be a predominant public health problem in India despite rapid strides made for its prevention, detection and treatment since ages. As leprosy can occur in any form due to immunological status of the patient, its clinico-pathological correlation gains more importance. Aim: The present research was undertaken to ascertain the importance of skin biopsy in detecting and diagnosing difficult cases where clinical diagnosis alone is not sufficient and a clinico-pathological correlation study in leprosy assumes greater significance. Method: This was a hospital based prospective study conducted in 60 cases of clinically diagnosed, newly untreated or suspected cases of leprosy for two years among patients attending OPD Department of Dermatology and whose skin biopsies were processed in the department of Pathology with Haematoxylin \& Eosin stain along with special stain (Fite Faraco) to ascertain clinico-pathological correlation in leprosy cases. Results: A total of 60 cases were studied. Out of them $71.7 \%$ were males and $28.3 \%$ females. Majority of them $31.7 \%$ belonged to the age group of 21-30 years and children were least affected. Clinico-histopathological classification concordance was noted maximum in LL (80\%) followed by BT (77.2\%), TT (76.4\%), BL (75\%), BB (71.4\%) and least in IL (60\%). Overall concordance between clinical and histopathological diagnosis observed in our study was 75\%. Conclusion: Diagnosing and treating leprosy solely on clinical basis still poses a problem while histopathology helps in making a definite diagnosis. This study shows a good correlation among clinical and histopathological findings in skin biopsy.
\end{abstract}

Keywords: hansen disease, communicable disease, Fite-Faraco staining, histopathology, acid fast bacilli, mycobacterium lepra

Cite This Article: Raveneet Badhan, Ramesh Kumar Kundal, Rakesh Tilak Raj, Rakesh Kumar Bahl, and Manjeet Singh Bal, "A Clinico-Pathological Correlation Study of Leprosy in a Tertiary Care Teaching Institute in Northwest Punjab, India.” American Journal of Medical Sciences and Medicine, vol. 2, no. 5 (2014): 99-108. doi: 10.12691/ajmsm-2-5-4.

\section{Introduction}

Leprosy is one of the oldest, chronic, granulomatous, infectious diseases having a prolonged incubation period that affects the skin and peripheral nerves. Its causative agent is Mycobacterium Leprae which parasitizes macrophages and Schawann cells. [1,2] The disease presents itself in different clinico-pathological forms depending upon the cellular immune system of the host.[3] Leprosy continues to be an important public health problem in most parts of Asia including India [4]. India achieved its elimination goal both at the national and state level with a prevalence rate [PR] of less than one case per 10,000 . But leprosy is still prevailing in this country. The year 2012-13 started with 0.83 lakh cases on record with a PR of 0.68 cases / 10,000. [5] The current situation in this country shows 1.35 lakh new cases per annum and thus, giving an annual new case detection rate (ANCDR) of
10.78 per one lakh. This showed an increase in annual new case detection rate of 4.5 from 2011-12. Punjab being a low endemic state having a prevalence rate of 0.21 cases / 10,000 in 2012-13 and an ANCDR of $0.35 \%$ or 2.46 cases /1 lakh [5] suggested that most cases detected in Punjab are due to the immigrants from high prevalent states. [6] The disease is still a growing epidemic [7] as its elimination is not as straightforward as it seemed. [8] The low endemic situation and overall reduction of cases pose a problem of their early detection and diagnosis. Atypical presentation of Hansen disease further makes it difficult. [6] Thus, the chance of missing the leprosy cases increases. A great deal in understanding of the Hansen disease has come from its histopathological correlation studies. Pathological examination not only helps in confirmation of the diagnosis but also helps in exact typing of the disease. $[9,10]$ A reliable diagnosis hinges around a good histopathological diagnosis and demonstration of acid fast bacilli(AFB) in histopathological sections. [10,11] Modified Fite's procedure has proved to be the most 
valuable in demonstrating leprae bacilli in tissues sections.[12] Due to its clinical diversity as well as its ability to mimic other diseases, leprosy is sometimes difficult to diagnose clinically, making histopathological examination a helpful diagnostic tool to confirm the diagnosis.[13] Clinical classification gives recognition only to gross appearances of the lesions, while parameters used in histopathological classification are precise taking into the account the progression and regression of disease under treatment. [14] Great variation in the interpretation of clinical and histopathological observations amongst various researchers in their studies prompted us to undertake this study. The present research was conducted to ascertain the importance of skin biopsy in detecting and diagnosing difficult cases where clinical diagnosis alone is not sufficient and therefore, in-depth knowledge and clarity regarding a clinico-pathological correlation in leprosy assumes greater significance.

\section{Materials and Methods}

A hospital based, prospective and observational study was conducted in a tertiary care teaching institute in Punjab [Northern India]. In this study, patients were enrolled over a period of two years from December 2011 to December 2013 after obtaining required approval from the institutional ethical committee. Ridley and Jopling classification was used by two dermatologists [RTR \& $\mathrm{RKB}$ ] to diagnose sixty cases, clinically as new cases of untreated leprosy. Skin biopsies of these patients were taken from the active lesions after taking their informed consent. A detailed clinical history and examination was carried out in the Department of Dermatology that was recorded in a predesigned proforma. Privacy and confidentiality of all these cases were maintained. The cases were selected from all new suspected, untreated cases of leprosy who visited the Department of Dermatology and reported to the Department of Pathology in Government Medical College and Hospital, Patiala; skin biopsies were carried out randomly on $4 \mathrm{~mm}$ specimens which were obtained either in elliptical or punch form (30 times each in both the groups).[15]. These biopsies were then immediately dispatched in toto to the pathology department in glass vials containing $10 \%$ buffered formalin. Following fixation of 12-24 hours, the skin biopsies were processed with histokinette as per the standard protocol in the Department of pathology and serial sections of $5 \mu$ thickness were cut. All these biopsies were stained with Haematoxylin \& Eosin and further stained by modified Fite-Faraco method for identification of Mycobacterial leprae. Bacterial indexes were calculated in the tissues biopsy specimen using Ridley's logarithmic method microscopically using an oil immersion objective (100X). [16] Skin slit smears were not done as skin biopsies were more reliable for acid fast bacilli (AFB) positivity. [17] Slides stained for AFB were read for a minimum of five minutes per section and bacilli noted as present or not, irrespective of their staining characteristics.[15] Histopathological evaluation was done by two pathologists (RB and RKK) independently who were blinded to clinical information and a clinicopathological correlation was carried out thus, eliminating bias. The correlation between clinical and pathological findings was evaluated as concordant or discordant. Histopathological criteria used for clinical correlation was the flattening of epidermis, involvement of sub-epidermal zone, character and extent of granuloma formation, density of lymphocytic infiltrate, nerve involvement, presence of M. Lepra(e) and epitheloid cells and other cellular elements in biopsy sections [18].

Inclusion criteria:

- Cases with hypo-pigmented lesions

- Cases with erythematous macule, patch, plaque and nodule

- along with thickened nerve or

- Anesthesia on the patch (es) or along the distribution of the nerve or

- Ulceration and limb deformities.

Exclusion criteria: [19]

- Cases with inadequate biopsies which did not include full depth of the dermis

- Patients already treated with antileprosy medication

- Cases showing features of reactional leprosy

- HIV positive cases, Pregnant women and Diabetic patients

- Patients on immunosuppressive drugs ( like corticosteroids etc)

- Children less than 12 year old.

The criteria of Ridley and Jopling $[16,18,19]$ were utilized to diagnosis and classify these cases clinically and histopathologically. Data were tabulated and shown as percentages. Chi-square test was used for statistical significance and p value $<0.05$ was considered significant for final statistical analysis using SPSS version 16.0.

180 cases of skin biopsies were reported in the pathology

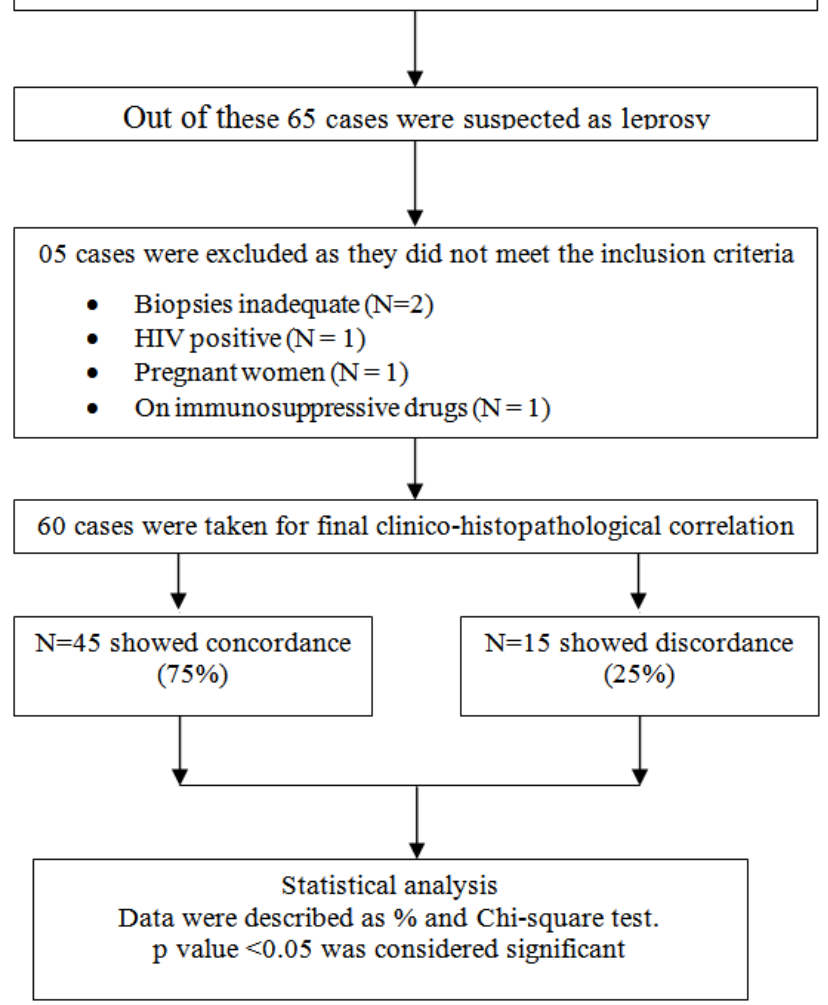

Flowchart 1. Study Design

\section{Results}


Sixty five clinically diagnosed new cases of untreated leprosy were included in this study; five cases were excluded as they did not fulfill inclusion criteria; two cases were not included due to inadequate biopsy( i.e. due to sampling error) and three cases (one case each was) were not considered due to exclusion criteria adopted [Flowchart-1]. All these five cases were negative for AFB on Fite-Faraco staining thus, excluding them from final evaluation. A total of 60 cases were analysed. The age distribution varied between 12-80years with a Male to female ratio of 2.5:1. The mean age of the study population was $35.6 \pm 13.7$ years. Majority of them 19 (31.7\%) belonged to the age group of 21-30 years followed by 17 (28.3\%) in age group of 31-40 years, the lowest incidence was observed in the age group of $<20$ years i.e. 7 (11.7\%). Among the total of 60 cases; 43(71.7\%) were males and $17(28.3 \%)$ females. The most frequent skin lesion present in this study group was hypo pigmented macule in $46(76.66 \%)$ of the cases, followed by anesthesia in 34(56.66\%) cases, nerve thickening in 23(38.8\%) cases, tropic ulcers were found in $3(5.0 \%)$ cases while combined lesions were present in $7(11.6 \%)$ cases. No limb deformities were seen in our study. The presenting complaints / symptoms of various types of leprosy are summarized in [Graph-A]. Duration of disease ranged one month to seven years. The mean duration of the study population was $7.6 \pm 18.4$ months.

Clinical categorization of 60 cases of leprosy according to Ridley and Jopling showed that the predominant group was Borderline tuberculoid (BT) in 22 cases (36.7\%) followed by tuberculoid (TT) in 17 cases (28.66\%), midborderline (BB) in 7 cases (11.66\%), lepromatous (LL) and indeterminate (IL) group in $5(8.33 \%$ cases) each while borderline lepromatous (BL) group was seen in 4(6.66\%) cases only. [Graph-B] Histopathologically majority of the cases in our study belonged to BT in 21(35\%) cases followed by TT in 15 (25\%) cases, BB in 9 (15\%) cases, IL in 7 (11.66\%) cases, LL and BL in 4 (6.66\%) cases each. [Table 1] Histological patterns observed in our study were epidermal changes in the form of thinning and atrophy (50\%), followed by normal epidermis (45\%) and ulcerative changes (5\%). Dermal infiltrate mainly consisted of infiltrate around NV bundles in $33 \%$, followed by infiltrate round Adnexa in $26.66 \%$, infiltrate round Arrector pilorum in $21 \%$ and combined infiltrate round Adnexal \& nerve in $18 \%$. [Table 2] 49 cases $(81.7 \%)$ were paucibacillary and $11(18.3 \%)$ cases were multibacillary on the basis of Modified Fite Faraco staining. [Table 3] Maximum clinico-histopathological correlation was present in LL (80\%),followed by BT (77.2\%), TT (76.4\%), BL(75\%), BB(71.4\%) and IL(60\%). Overall Clinico-histopathological concordance in present study was $75 \%$ [Table 4]. It has been seen that clinical diagnosis and histopathological observations of different types of leprosy were correlating well in this study $(\mathrm{p}<0.05)$ and its concordance is depicted in Table 2. The data was statistically analyzed using Pearson chi-square with a p-value of 151.022 at DF of 25 with a likelihood ratio of 102.929 at $25 \mathrm{DF}$ of table value 0.000 (asymp.Sig 2 sided) is highly significant.

Table 1. Clinico-histopathological correlation as per Ridley and Jopling classification [18]

\begin{tabular}{|c|c|c|c|c|c|c|c|c|c|}
\hline \multirow{2}{*}{$\begin{array}{c}\text { Clinical } \\
\text { type }\end{array}$} & \multirow{2}{*}{$\begin{array}{c}\begin{array}{c}\text { Clinically diagnosed } \\
\text { cases }\end{array} \\
\text { Number } \\
\end{array}$} & \multicolumn{6}{|c|}{$\begin{array}{c}\text { Histopathological breakup of clinically } \\
\text { diagnosed cases }\end{array}$} & \multirow[t]{2}{*}{$\begin{array}{c}\% \text { of } \\
\text { concordance }\end{array}$} & \multirow[t]{2}{*}{$\begin{array}{c}\% \text { of } \\
\text { discordance }\end{array}$} \\
\hline & & TT & BT & BB & BL & LL & IL & & \\
\hline TT & 17 & 13 & 2 & 1 & 0 & 0 & 1 & $76.4(13 / 17)$ & $23.5(4 / 17)$ \\
\hline BT & 22 & 1 & 17 & 2 & 0 & 0 & 2 & $77.2(17 / 22)$ & $22.7(5 / 22)$ \\
\hline BB & 7 & 0 & 1 & 5 & 0 & 0 & 1 & 71.4 (5/ 7) & $\begin{array}{c}28.5 \\
(2 / 7) \\
\end{array}$ \\
\hline BL & 4 & 0 & 0 & 1 & 3 & 0 & 0 & 75 (3/ 4) & $25(1 / 4)$ \\
\hline LL & 5 & 0 & 0 & 0 & 1 & 4 & 0 & $\begin{array}{c}80 \\
(4 / 5) \\
\end{array}$ & 20 (1/ 5) \\
\hline IL & 5 & 1 & 1 & 0 & 0 & 0 & 3 & $60(3 / 5)$ & $40(2 / 5)$ \\
\hline Total & 60 & 15 & 21 & 9 & 4 & 4 & 7 & 45 & 15 \\
\hline Overall \% & $\begin{array}{c}100 \% \\
(60 / 60) \\
\end{array}$ & $\begin{array}{c}25 \% \\
(15 / 60) \\
\end{array}$ & $\begin{array}{c}35 \% \\
(21 / 60) \\
\end{array}$ & $\begin{array}{c}15 \% \\
(9 / 60) \\
\end{array}$ & $\begin{array}{l}6.66 \% \\
(4 / 60) \\
\end{array}$ & $\begin{array}{l}6.66 \% \\
(4 / 60) \\
\end{array}$ & $\begin{array}{c}11.66 \% \\
(7 / 60)\end{array}$ & $\begin{array}{c}75 \% \\
(45 / 60) \\
\end{array}$ & $\begin{array}{c}25 \% \\
(15 / 60) \\
\end{array}$ \\
\hline
\end{tabular}

Table 2. Summary of main histopathological findings of all suspected cases of leprosy

\begin{tabular}{|c|c|c|c|c|c|c|c|}
\hline Histopathology of the cases & TT & BT & BB & BL & LL & IL & Total (\%) \\
\hline Number of cases & 15 & 21 & 9 & 4 & 4 & 7 & 60 \\
\hline \multicolumn{8}{|c|}{ Epidermal changes } \\
\hline Normal & 4 & 12 & 6 & 2 & 0 & 3 & $27(45 \%)$ \\
\hline Atrophic & 11 & 7 & 2 & 2 & 4 & 4 & $30(50 \%)$ \\
\hline Ulcerative & 0 & 2 & 1 & 0 & 0 & 0 & $3.0(5 \%)$ \\
\hline \multicolumn{8}{|c|}{ (Lymphocytes aggregates around) } \\
\hline Arrector pilorum & 4 & 8 & 1 & 0 & 0 & 0 & $13(21.0 \%)$ \\
\hline Adnexa, & 5 & 6 & 2 & 1 & 1 & 1 & $16(26.66 \%)$ \\
\hline $\mathrm{NV}^{\complement}$ bundles & 4 & 4 & 4 & 2 & 2 & 4 & $20(33.0 \%)$ \\
\hline Adnexa, and $\mathrm{NV}^{\complement}$ bundles infiltrates & 2 & 3 & 2 & 1 & 1 & 2 & $11(18.33 \%)$ \\
\hline Compact epitheloid granuloma & 10 & 15 & 0 & 0 & 0 & 0 & $25(41.66 \%)$ \\
\hline Diffuse epitheloid granuloma & 0 & 0 & 1 & 0 & 0 & 0 & $1.0(1.6 \%)$ \\
\hline Foamy macrophages/ histocytes & 0 & 0 & 8 & 4 & 4 & 0 & $16(26.66 \%)$ \\
\hline Giant cells & 5 & 6 & 0 & 0 & 0 & 0 & $11(18.33 \%)$ \\
\hline Loose histocytes aggregates & 0 & $21 *$ & 7 & 0 & 0 & 0 & $28(46.67 \%)$ \\
\hline Grenz zone & 0 & 0 & 9* & 4* & 4* & 0 & $(28.33 \%)$ \\
\hline
\end{tabular}

*Values indicate that these findings were present in the same slide under the heading where it is mentioned, therefore, the value is taken for more than one column in the table for calculation purpose.

$\mathrm{NV}^{\mathfrak{\complement}}=$ neurovascular 
Table 3. Distribution of AFB in clinically diagnosed cases with modified Fite Faraco Stain

\begin{tabular}{|c|c|c|c|c|c|c|c|c|}
\hline \multirow{2}{*}{ Lesions on HPE } & \multirow{2}{*}{ Number of cases } & $\mathbf{P B}$ & \multicolumn{7}{|c|}{ Bacterial index by modified Fite Faraco Stain (MB) } \\
\cline { 3 - 9 } & & $\mathbf{0}$ & $\mathbf{1 +}$ & $\mathbf{2 +}$ & $\mathbf{3 +}$ & $\mathbf{4 +}^{+}$ & $\mathbf{5 +}$ & $\mathbf{6 +}$ \\
\hline TT & 15 & 15 & 0 & 0 & 0 & 0 & 0 & 0 \\
\hline BT & 21 & 21 & 0 & 0 & 0 & 0 & 0 & 0 \\
\hline BB & 9 & 6 & 0 & 1 & 2 & 0 & 0 & 0 \\
\hline BL & 4 & 0 & 0 & 0 & 1 & 2 & 1 & 0 \\
\hline LL & 4 & 0 & 0 & 0 & 0 & 1 & 2 & 1 \\
\hline IL & 7 & 7 & 0 & 0 & 0 & 0 & 0 & 0 \\
\hline Total & 60 & 49 & 0 & 1 & 3 & 3 & 3 & 1 \\
\hline$\%$ age & $100 \%$ & $49 / 60(81.7 \%)$ & & & $11 / 60(18.2 \%)$ & \\
\hline
\end{tabular}

Table 4. A comparative study of correlation by various authors with the present study

\begin{tabular}{|c|c|c|c|c|c|c|c|}
\hline Comparative study & Present study & $\begin{array}{c}{[26]} \\
\text { Bijjaragi et al } \\
\end{array}$ & $\begin{array}{c}{[14]} \\
\text { Shiva-swamy et al }\end{array}$ & $\begin{array}{c}{[27]} \\
\text { Mathur et al }\end{array}$ & $\begin{array}{c}19] \\
\text { Sharma A et al } \\
\end{array}$ & $\begin{array}{c}{[24]} \\
\text { Moorthy et al }\end{array}$ & $\begin{array}{c}{[25]} \\
\text { Bhatia AS et al }\end{array}$ \\
\hline Year and type of leprosy & 2014 & 2012 & 2011 & 2011 & 2008 & 2001 & 1993 \\
\hline No. of cases & 60 & 171 & 136 & 140 & 270 & 372 & 1272 \\
\hline TT & 76.4 & 75 & 56 & 73.2 & 47.37 & 46.15 & 50 \\
\hline BT & 77.2 & 57.3 & 64.1 & 89.7 & 53.01 & 66.66 & 77 \\
\hline$B B$ & 71.4 & 16.7 & 50 & 66.7 & 37.35 & 50 & 25 \\
\hline BL & 75 & 40 & 73.3 & 72.4 & 58.82 & 70 & 43 \\
\hline LL & 80 & 76.9 & 84.2 & 95.2 & 75.86 & 80 & 91 \\
\hline IL & 60 & 66.7 & 50 & - & 100 & 20 & 35 \\
\hline Overall concordance (\%) & 75 & 57.3 & 74.5 & 80.4 & 53.44 & 62.63 & 69 \\
\hline
\end{tabular}

\section{Discussion}

The most common accepted classification by research workers is that of Ridley and Jopling which is primarily based on immunity but has been correlated well with clinical, histopathological and bacterial findings. Despite having such an accurate classification, the results of different studies have not been uniform and showed so many diversities between the clinical and histopathological features. [18,20] In the present study, Ridley-Jopling classification was used to classify leprosy in all cases clinically and histopathologically. [16,18,19] Indeterminate cases of leprosy were also included for analysis. $[14,17,20]$ Most common age group affected was 21-30 years in $31.7 \%$. The youngest and the oldest persons taken in the study were in the age group of 12-80 years which was comparable with the study of Manandhar et al. [20]. Male predominance was seen in $71.7 \%$ of the cases in our study with similar results from Giridhar $\mathrm{M}$ et al. [17] and Manandhar et al. [20] due to better awareness amongst them than their counterparts. The most frequent skin lesion present was hypo-pigmented macule in $76.66 \%$ of the patients correlating well with the study of Ocampo and Franciso [21] Most common sites chosen for biopsies were Arms in 19 (31.66\%) cases, forearms in 14 (23.33\%) cases, hands in $10(16.66 \%)$ cases, back in $9(15 \%)$ cases, lower limbs in $8(13.33 \%)$ cases showing similar results by Giridhar $\mathrm{M}$ et al. [17] Histological evidence of leprosy was established in agreement with $95 \%$ of the cases by two pathologists who were blinded to clinical information which is similar to the study of Ocampo and Franciso (96.85\%) [21]. However, overall agreement in clinico-pathological concordance was 75\%. Family history of definite contact was present in $5 \%$ of the cases which was lower compared to the study of Thakkar and Patel [22].

In the present study, modified Fite Faraco stain positivity for AFB was $18.2 \%$ of the skin biopsies which was comparable to the study of Manandhar et al [20] AFB positivity strongly correlated with lepromatous pole $(100 \%)$. However, Fite stain has little role if smears are with few or scanty bacilli, which are likely to be missed. [23] In cases of overlap modified fite Faraco stain in correlation with clinical and histopathological features is more useful for accurate typing of leprosy. [24]

Histological patterns observed in our study were epidermal changes in the form of thinning and atrophy (50\%), followed by normal epidermis (45\%) and ulcerative changes (5\%). Epitheloid cell granuloma (41.66\%) and gaint cells (18.33\%) were more common towards tuberculoid pole whereas foamy macrophages (26.66\%) with clear subepidermal grenz zone (42.5\%) were more common towards lepromatous pole.[18] Dermal infiltrate mainly consisted of infiltrate around Neurovascular (NV) bundles in 33\%, followed by infiltrate round Adnexa in 26.66\%,infiltrate round Arrector pilorum in $21 \%$ and combined infiltrate round Adnexal \& nerve in $18 \%$. These features were in contrast to Thappa and Jha [13] who observed epidermal changes in $29.5 \%$, granuloma in $42 \%$, adnexal infiltrate in $7 \%$, nerve infiltrate in 11\%, combined adnexal and nerve infiltrate in $6 \%$. Dermal infiltrate in $46.4 \%$ cases constituted of lympho-histocytes in their study while it correlating well with our study (46.7\%).

In our study clinical spectrum of leprosy revealed maximum cases in borderline group [BT+BL+BB] $(55 \%)$ [Figure 1, Figure 2] followed by TT (28.66\%), [Figure 3] LL and IL (8.33\%) group each; in agreement with predominance of BT group as recorded by Moorthy BN et al. [24] and Sharma A et al [19]. 


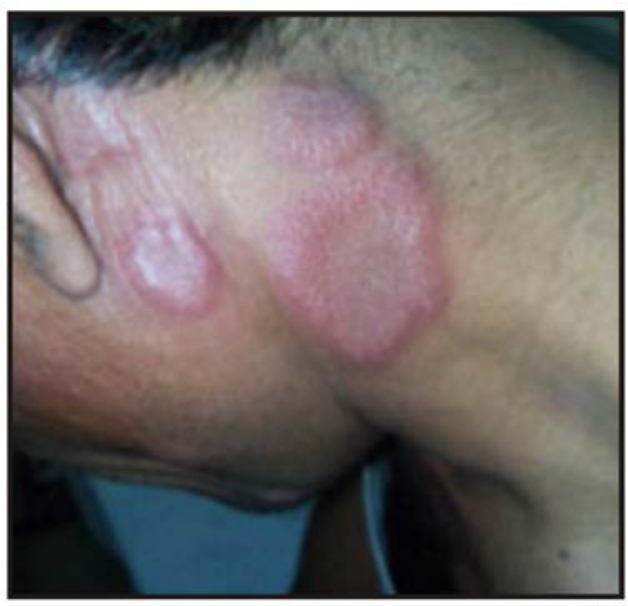

(a)

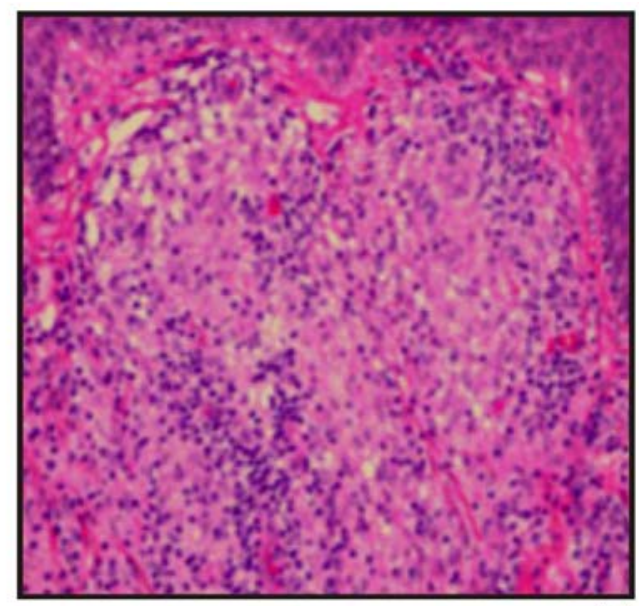

(b)

Figure 1a. showing multiple, erythematous, annular and punched out lesions over the side of neck and face (BB) Courtesy: Dr Rakesh Tilak Raj. Senior Resident, Department of Dermatology, Venereology and Leprosy, Government Medical College, Patiala (Punjab)-India; b. PHOTOMICROGRAPH OF MIDBORDERLINE LEPROSY SHOWING FOAMY MACROPHAGES MIXED WITH LYMPHOCYTIC INFILTRATION EXTENDING UPTO EPIDERMIS H \& E X 100 Courtesy: Dr Ramesh Kumar Kundal, Professor, Department of Pathology, Government Medical College, Patiala

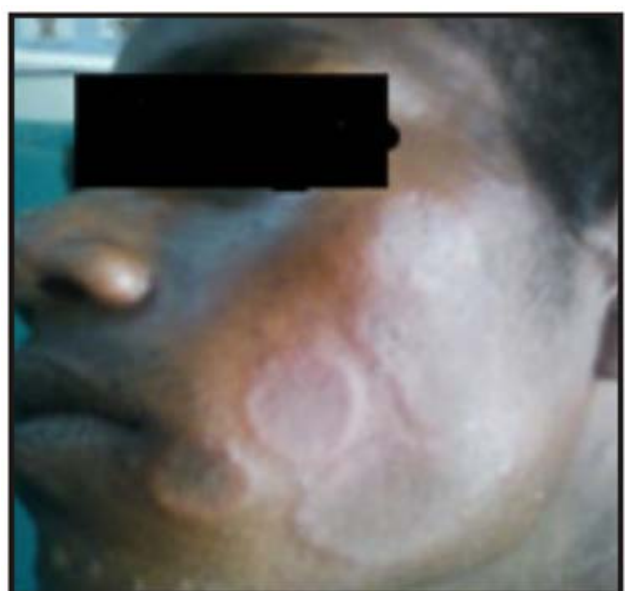

(a)

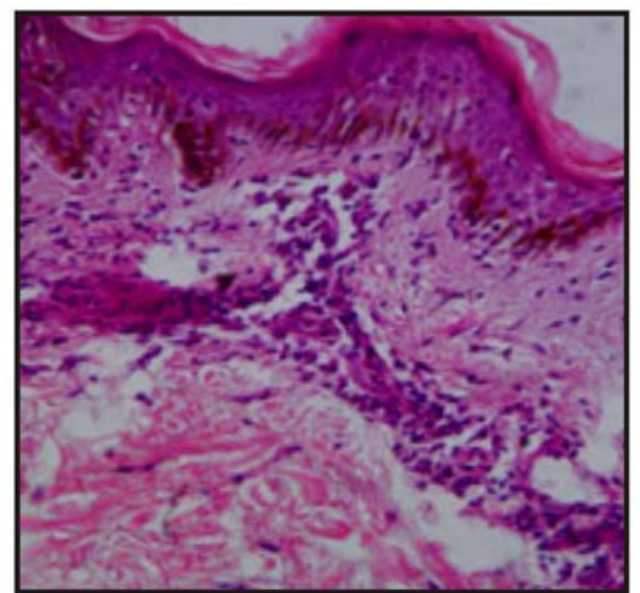

(b)

Figure 2a. Figure showing multiple, skin colored to erythematous, annular plaques along with satellite lesions involving the face. (BT) Courtesy: Dr Dr Rakesh Tilak Raj. Senior Resident, Department of Dermatology, Venereology and Leprosy, Government Medical College, Patiala (Punjab)-India; b. PHOTOMICROGRAPH OF BORDERLINE TUBERCULOID TYPE OF LEPROSY SHOWING LYMPHOCYTIC INFILTRATION UPTO EPIDERMIS H\&E STAIN X 400 Courtesy: Dr Ramesh Kumar Kundal, Professor, Department of Pathology, Government Medical College, Patiala

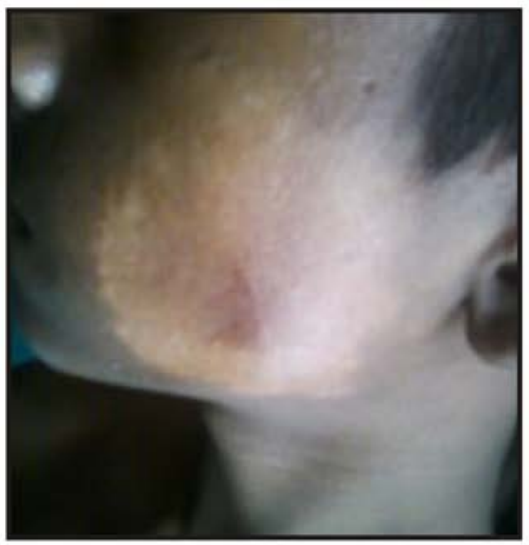

(a)

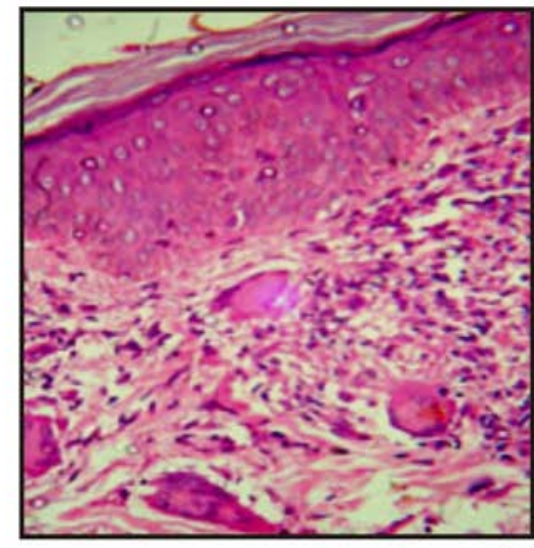

(b)

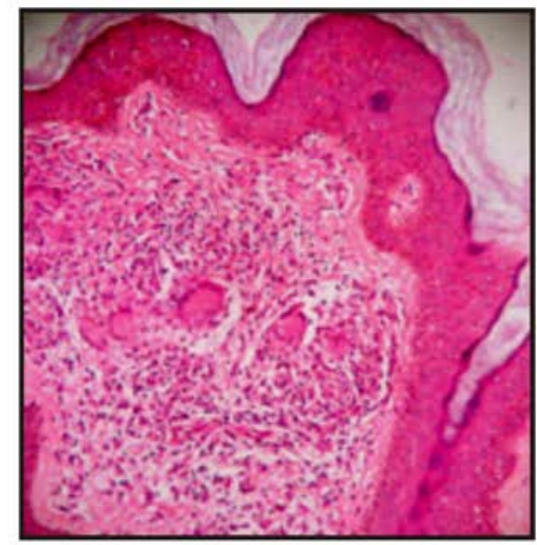

(c)

Figure 3a. showing well define dry, hypo-pigmented plaque over the face with loss of sensation (TT) Courtesy: Dr Dr Rakesh Tilak Raj. Senior Resident, Department of Dermatology, Venereology and Leprosy, Government Medical College, Patiala (Punjab)-India; b. PHOTOMICROGRAPH OF TUBERCULOID TYPE OF LEPROSY SHOWING EPITHELIOID GRANULOMAS WITH SCATTERED LANGHANS GIANT GELLS AND LYMPHOCYTIC INFILTRATES (H \& E STAIN X 100) Courtesy: Dr Ramesh Kumar Kundal, Professor, Department of Pathology, Government Medical College, Patiala; c. PHOTOMICROGRAPH OF TUBERCULOID LEPROSY SHOWING NUMEROUS LANGHANS GIANT GELLS AMIDST LYMPHOCYTIC INFILTRATES (H \& E STAIN X 100) Courtesy: Dr Ramesh Kumar Kundal, Professor, Department of Pathology, Government Medical College, Patiala 
According to our study, the most common clinicohistopathological subtype was LL and the least common was IL correlating well with their histopathologies (80\%, $60 \%)$. Moorthy BN et al. (80\%, 20\%) [24], Shivaswamy et al. (84.2\%, 50\%) [14] Observed similar findings in their studies but this study is in contrast to Bhatia AS et al. (91\%, 35\%) [25] who observed better correlation in his study.

Maximum parity had been observed in lepromatous leprosy (LL) in various studies by Moorthy et al. (80\%),

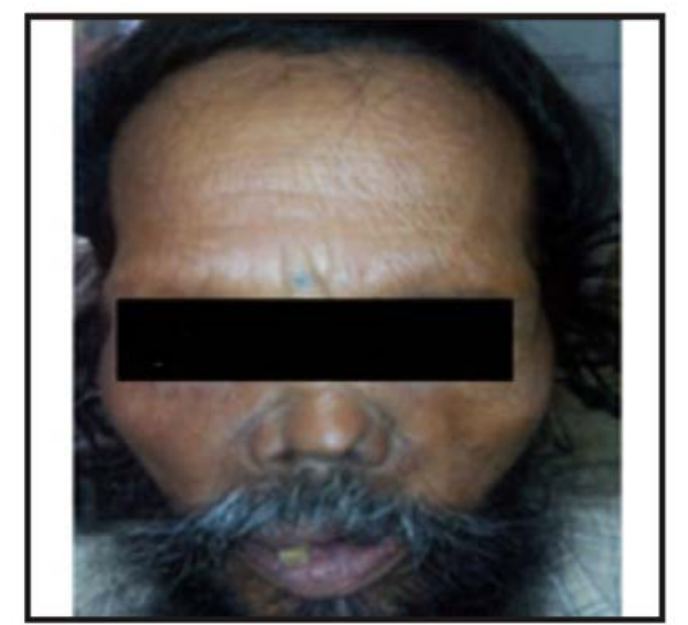

(a)

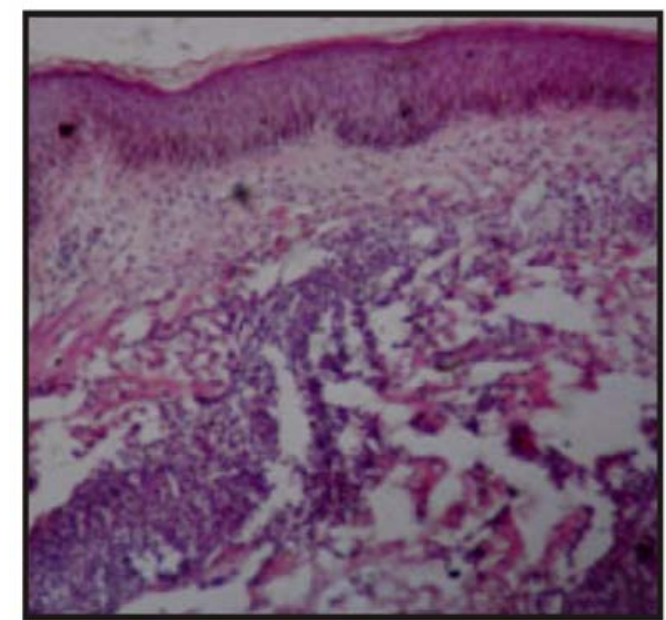

(c)
[24] Sharma A et al. (75.8\%) [19], Shivaswamy et al. (84.2\%) [14], Bijjaragi et al. [26] (76.9\%) and Mathur et al. [28] (80.4\%) which is at par with our study, as we have also observed a higher correlation in LL (80\%). [Figure 4] This is in contrast to Bhatia AS et al. [25] (91\%) and Mathur et al. [27] (95\%) showing highest correlation in their studies while Vargas-ocampo and Barbosa et al. showing lowest correlation [21,15] (42.9\% and 57\%) in their studies.

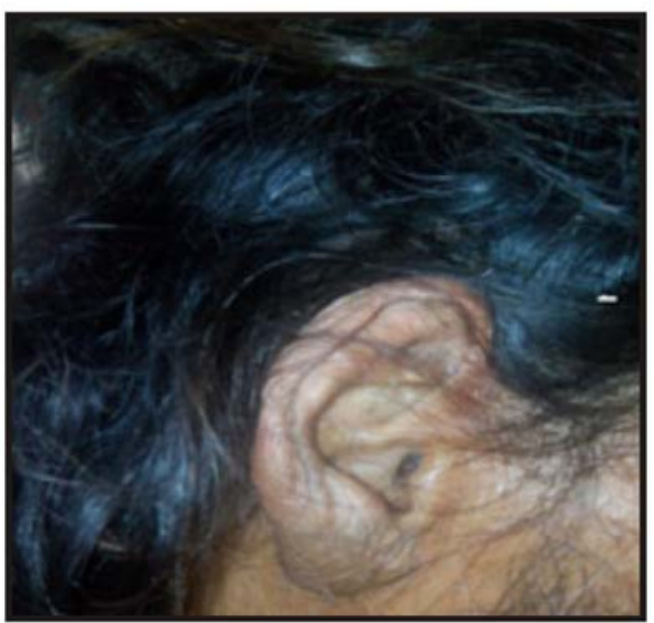

(b)

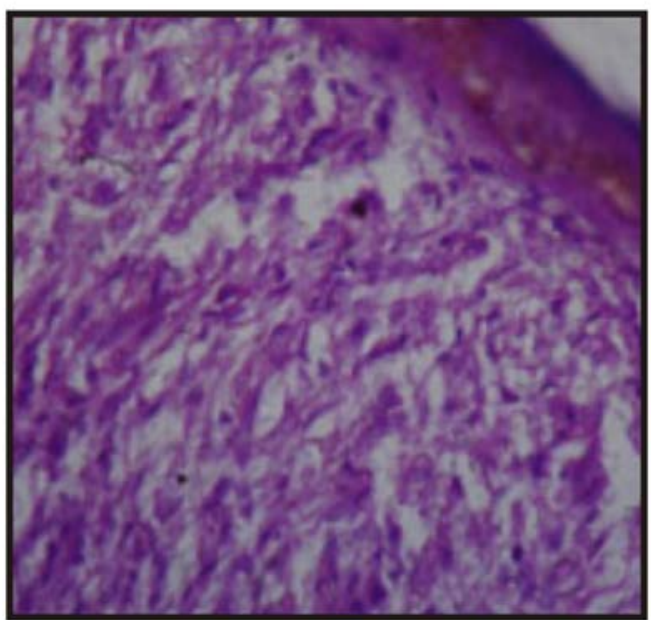

(d)

Figure 4a\&b. showing nasal deformity along with infiltration of forehead and ears along with madrosis (LL) Courtesy: Dr Dr Rakesh Tilak Raj. Senior Resident, Department of Dermatology, Venereology and Leprosy, Government Medical College, Patiala (Punjab)-India; c. PHOTOMICROGRAPH OF LEPROMATOUS TYPE OF LEPROSY SHOWING, GRENZ ZONE, FOMAY MACROPHAGES H\&E X 100 Courtesy: Dr Ramesh Kumar Kundal, Professor, Department of Pathology, Government Medical College, Patiala; d. PHOTOMICROGRAPH OF LEPROMATOUS TYPE OF LEPROSY SHOWING GRENZ ZONE AND FOMAY MACROPHAGES H\&E X 400 Courtesy: Dr Ramesh Kumar Kundal, Professor, Department of Pathology, Government Medical College, Patiala

Low parities were observed by us in TT group (76.4\%) followed by BL (75\%) [Figure 5] and BB (71.4\%) group which is in contrast to observations observed by Sharma A et al. [19], Shivaswamy et al. [14] Mathur et al in their studies. [27] but showing similarity with the studies of Bijjaragi et al. [26] and Bhatia AS et al [25].

Minimal parity was seen in IL (60\%) [Figure 6] in our study due to non-specific histology of the lesions showing similarity with the study of Bijjaragi et al. (66.7\%) [26].

Our concordance was better than the studies of Bhatia AS et al. (35\%) [25] and Moorthy et al. (20\%) [24] but was in contrast to studies of Sharma A et al. [19] (100\%) who showed highest parity in their study while Moorthy et al. and Bhatia AS et al. [24,25] showed lowest parities in their studies.

We observed better correlation in BB group compared to all other studies [19,24,25,26,27]. Overall Clinicohistopathological concordance in present study was $75 \%$ while overall disparity was $25 \%$. It was more common in IL (40\%) than BB (28.5\%) group. Percentage of clinicohistopathological correlation accuracy reported in various studies by various authors ranged from 53.44-80.4\% $[14,19,24,25,26,27]$ as depicted in Table 4. The discordance was due to the fact that the clinical diagnosis was made on the basis of Ridley and Jopling classification without its histopathological confirmation [25] and due to 
variations in immunological status making them shift from

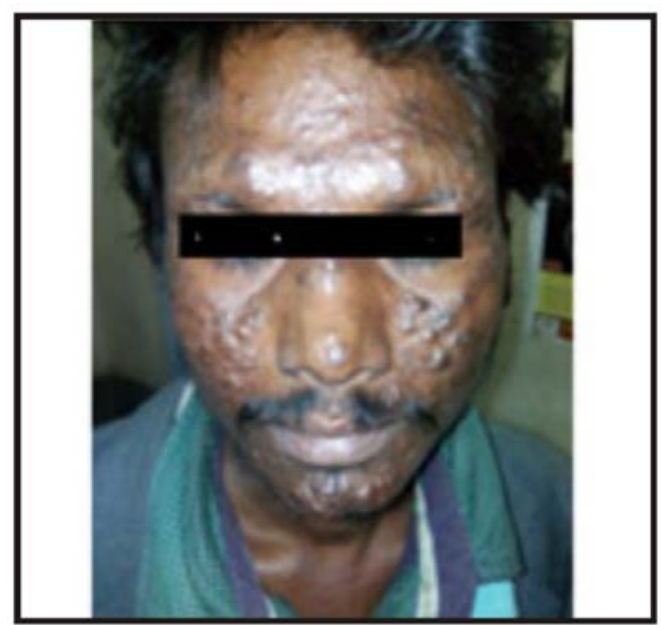

(a)

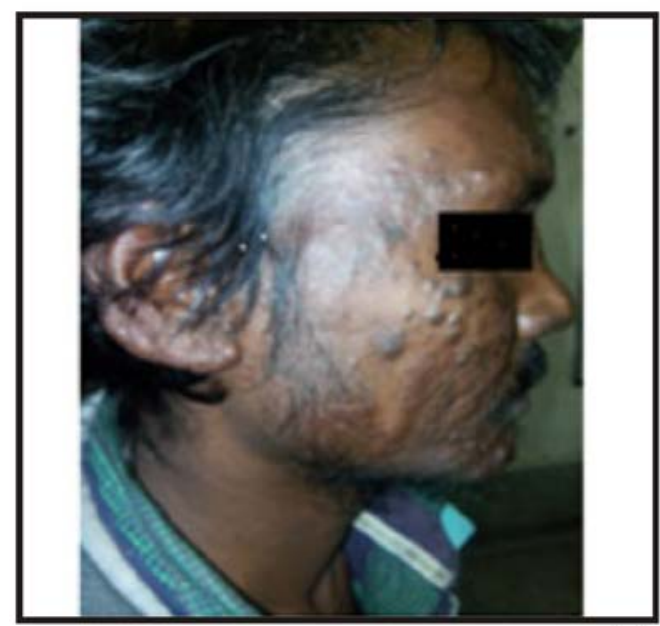

(c) one spectrum to another with/ without treatment.

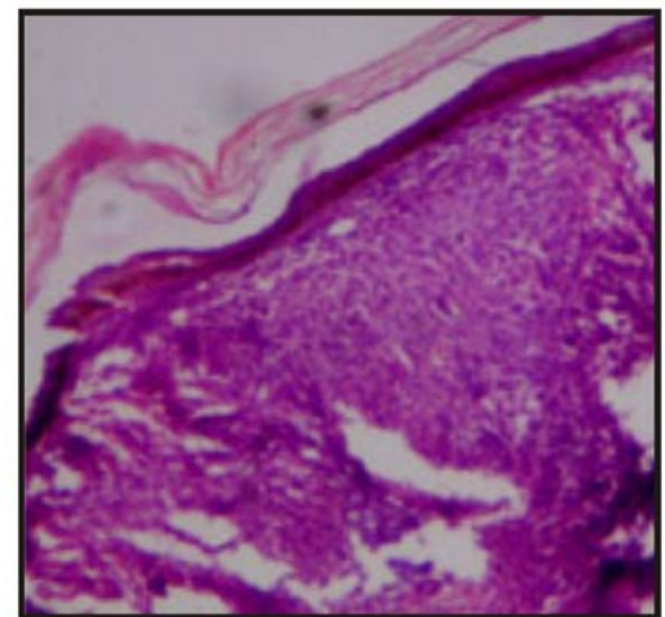

(b)

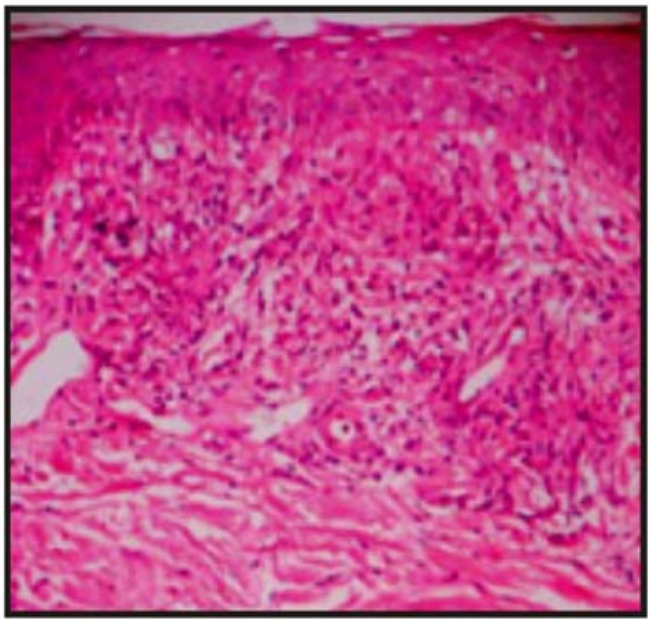

(d)

Figure 5a\&b. showing multiple skin colored plaques and nodules involving the face (BL) [B] showing ear lobule involvement in the same patient. Courtesy: Dr Dr Rakesh Tilak Raj. Senior Resident, Department of Dermatology, Venereology and Leprosy, Government Medical College, Patiala (Punjab)-India; c. PHOTOMICROGRAPH OF BOEDERLINE LEPROMATOUS TYPE OF LEPROSY SHOWING ATROPHIC EPIDERMIS, GRENZ ZONE AND LYMPHOCYTIC INFILTRATE WITH FOMAY MACROPHAGES H\&E X 100 Courtesy: Dr Ramesh Kumar Kundal, Professor, Department of Pathology, Government Medical College, Patiala; d. PHOTOMICROGRAPH OF BOEDERLINE LEPROMATOUS TYPE OF LEPROSY SHOWING LYMPHOCYTES ADMIXED WITH FOMAY MACROPHAGES H\&E X 100 Courtesy: Dr Ramesh Kumar Kundal, Professor, Department of Pathology, Government Medical College, Patiala

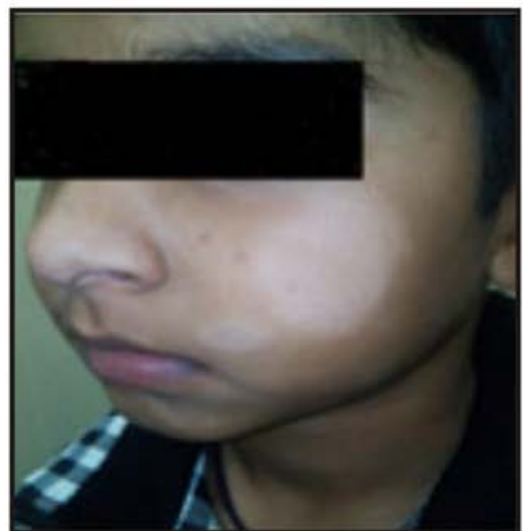

(a)

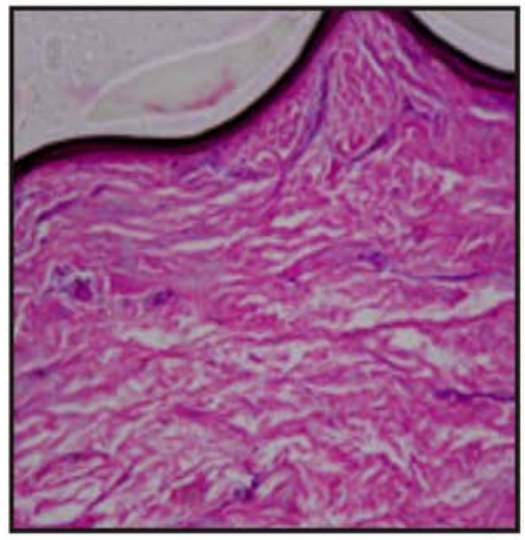

(b)

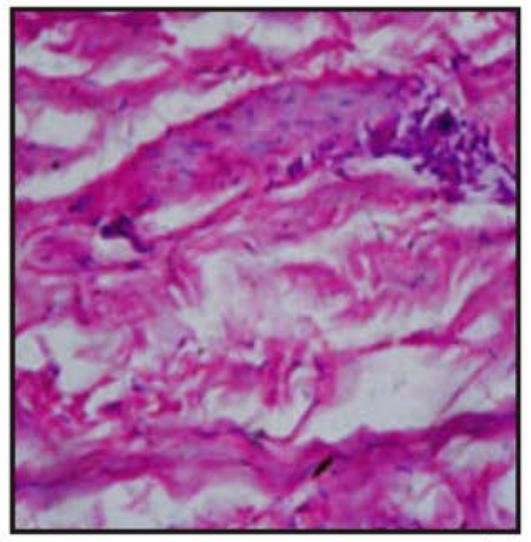

(c)

Figure 6a. showing ill-define dry, hypo-pigmented patch over the face (IL) Courtesy: Dr Dr Rakesh Tilak Raj. Senior Resident, Department of Dermatology, Venereology and Leprosy, Government Medical College, Patiala (Punjab)-India; b. PHOTOMICROGRAPH OF INDETERMINATE TYPE OF LEPROSY SHOWING LYMPHOCYTIC INFILTRATION IN DERMIS H\&E X 100 Courtesy: Dr Ramesh Kumar Kundal, Professor, Department of Pathology, Government Medical College, Patiala; c. PHOTOMICROGRAPH OF INDETERMINATE TYPE OF LEPROSY SHOWING LYMPHOCYTIC INFILTRATION ADJACENT TO NERVE H\&E X 400 Courtesy: Dr Ramesh Kumar Kundal, Professor, Department of Pathology, Government Medical College, Patiala 
Histopathologically change of classification was seen in $40 \%(2 / 5)$ cases in IL, 28.55\% (2/7) cases in BB, 25\% $(1 / 4)$ cases in BL, 20\% (1/5) cases in LL, 23.5\% (4/17) cases in $\mathrm{TT}$ and $22.7 \%(5 / 22)$ cases in BT. Maximum change of classification was seen in IL and BB groups due to continuously changing immune system. The changes of classification in regard to their respective groups were that in TT group 4 cases (2BT, $1 \mathrm{BB}, 1 \mathrm{BL})$, in $\mathrm{BT}$ group 5 cases (1TT, 2BB, 2IL), in BB group 2 cases (1BT, 1IL), in BL group 1 case $(1 \mathrm{BB})$, in LL group 1 case (1BL) and in IL group 2 cases (1TT, 1BT). Similar findings were also observed in the study of Bhatia AS et al [25].

However, concordance differed variably across the spectrum when compared to other studies which may be due to more precise criteria laid down in histopathology, confirming that lesions were easy to diagnose towards lepromatous pole clinically as well as histopathologically. [14] Clinical diagnosis of early leprosy lesions offers difficulties even to the experienced dermatologists and Leprologists. [25] Hence, histopathological study is very important in understanding the disease, its varied manifestations and complications and histopathological diagnosis when available is deemed to be the gold standard for leprosy diagnosis. [24] Inter-observer variation, immune status of the patient, different selection criteria, size of biopsy, depth of biopsy, quality of section, method of staining [Figure 7] age of the lesion etc. has vital role in histopathological evaluation. [28] In discordant cases, 5(33.3\%) cases were of nonspecific dermatitis, 5 (33.3\%) cases were of polymorphic light eruption, 3 (20\%) cases were of sarcoidosis and 2 (13\%) cases were of fungal infection.

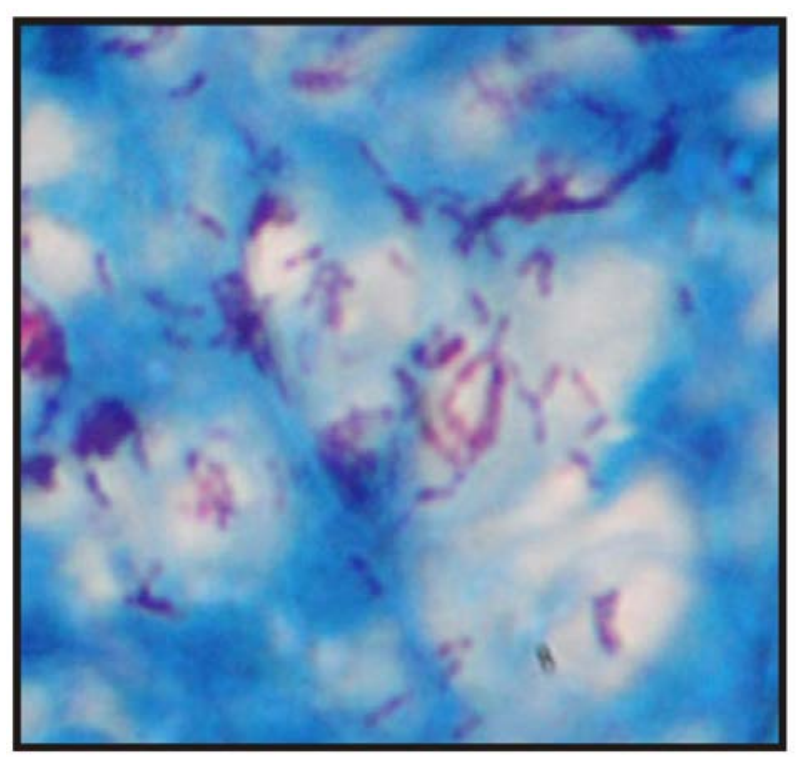

Figure 7. PHOTOMICROGRAPH SHOEING CLUMPS OF LEPRA (AFB) BACILLI IN LEPROMATIONS LEPROSY TYPE OF LEPROSY FITE FARACO STAIN X 1000 Courtesy: Dr Ramesh Kumar Kundal, Professor, Department of Pathology, Government Medical College, Patiala

\section{Conclusion}

Diagnosing and treating leprosy solely on clinical basis still poses a problem in developing countries where advanced diagnostic techniques are lacking and reliability solely on slit skin smear may lead to poor diagnosis increasing false negative diagnosis. Henceforth, histopathology confirmation of suspected cases of leprosy helps in making a definite diagnosis. Skin biopsy remains the gold standard even today in these situations. This study shows a good correlation $(75 \%$, p-value $<0.05$ ) between clinical and histopathological findings in skin biopsy of clinically diagnosed new cases of leprosy. It not only helps in leprosy control rather it prevents the deformity and transmission of disease further in the society.

\section{Implications of the Study}

Diagnosing solely on the clinical basis will lead to error in cases of Indeterminate, borderlines leprosy where both under and over diagnosis of leprosy can occur posing difficulties in classification and treatment. Therefore, we suggest that histopathological correlation offers better results by taking series of biopsies out of the same lesion during the follow-up of leprosy which plays a crucial role in early detection and better management of this disease.

\section{Limitations of the Study}

Small sample size was the main limitation of this study. Immune status of the patients could not be assessed due to non-availability of diagnostic equipments. Skin biopsy in itself is not sufficient to provide definitive diagnosis in all suspected cases of leprosy. Therefore, better diagnostic techniques if available must be adopted (like molecular studies, PCR, serological tests, immuno-histochemistry) to confirm the diagnosis whenever there is disparity between the skin biopsy and clinico-histopathological correlation to avoid detection of missing cases and to prevent their inadequate treatment.

\section{Source of Funding}

None.

\section{Conflict of Interest}

None.

\section{Acknowledgment}

We thank all the post-graduate students of Department of Dermatology and pathology in helping us to accomplish this research.

\section{References}

[1] Scollard, D.M., Adams, L.B., Gillis, T.P., Kranenbunthl, J.L., Truman, R.W. et al., The continuing challenges of leprosy, Am Soc Microbiol, 49. 338-348. 2006.

[2] Song, S.P., Elias, P.M., Lv, C.Z., Shi, Y.J., Guang, P., Zhang, X.J. et al., Decreased cutaneous resonance running time in cured leprosy subjects, Skin Pharmacol Physiol, 22. 218-224. 2009. 
[3] Abulafia, J., Vignale, R.A, Leprosy: Pathogenesis updated, Int J Dermatol, 38. 321-334. 1999.

[4] Mohite, R.V., Mohite, V.R., Durgawale, P.M, Differential Trend of Leprosy in Rural and Urban Area of Western Maharashatra, Indian J Lepr, 85. 11-18. 2013.

[5] Progress report as on 31 $1^{\text {st }}$ March 2012-National Leprosy Eradication Programme. Central Leprosy Division, Directorate General of Health Services, Government of India, New Delhi110011.

[6] Training Manual for Medical Officers National Leprosy Eradication Programme Directorate General of Health Services Ministry of Health \& Family Welfare. Nirman Bhawan, New Delhi, 2009. Available at http://nlep.nic.in/pdf/Leprosy\%20manual.pdf assessed on 04 Oct 2014 at 11:10am.

[7] Moreira, M.V., Waldman. E.A., Martins, C.L, Leprosy in Espinto santo-state Brazil; a growing endemic, Cad Saude Publica, 24(7). 1619-1630. 2008.

[8] Saunderson, P.R, Leprosy elimination not as straight forward as it seemed, Public Health Res, 123(2). 213-216. 2008.

[9] Chacko, C.J.G, "Leprosy: Pathology". In: Valia RG, Valia AR. Ed. Textbook and Atlas of Deramtology, $1^{\text {st }}$ edition, Bombay, Bhalani Publishing House, 1994. 1340-1349.

[10] Lucus, S.B., Ridley, D.S, The use of histopathology in leprosy diagnosis and research, Lepr Rev, 60. 257-62. 1989.

[11] Nayak, S.V., Shivarudrappa, A.S., Nagarajapa, A.H., Ahmed, S.M, Role of modified rapid AFB method in histopathological sections of Hansen disease, Ind J Dermatol Venerol Leprol, 69. 173-174. 2003.

[12] Job, C.K., Chacko, C.I.G, A modification of Fite's stain for demonstration of M leprae in tissues sections, Int J Lepr, 58. 1719. 1986.

[13] Thapa, D.P., Jha, A.K, Clinico-histopathological correlation in leprosy: A tertiary care hospital based study, Our Dermatol Online, 4(3). 294-296. 2013.

[14] Shivaswamy, K.N., Shyamprasad, A.L., Sumathy, T.K. et al., Clinical and histopathological correlation in leprosy. Dermatol Online Journal, 18(9). 2. 2012.

[15] Barbosa, A.A. Jr., Jamberio, J., Cirqueria, J.S.O., Silva, T.C, Retrospective histopathological classification of 1108 skin biopsies from patients clinically suspected of having leprosy from
Bahia, Northeast Brazil, Rev. Soc. Bras. Med. Trop, 31. 533-537. 1998.

[16] Jopling, W.H, Mcdougall AC, Diagnostic Tests, In: Handbook of leprosy. $5^{\text {th }}$ edn. New Delhi, CBS publishers, 60. 1999.

[17] Giridhar, M., Arora, G., Lajpal, K., Chahal, K.S, Clinicopathological concordance in Leprosy - A clinical, histopathological and bacteriological study of 100 cases, Indian $J$ Lepr, 84. 217-225. 2012.

[18] Ridley, D.S., Jopling, W.H.O, Classification of leprosy according to immunity. A five group system, Int J Lepr Other Mycobacterial Dis, 34. 255-273. 1996.

[19] Sharma, A., Sharma, R.K., Goswami, K.C., Bharadwaj, S, Clinical and histopathological correlation in leprosy, JK Science, 10(3). 120-123. 2008.

[20] Manadhar, U., Adhikari, R.C., Sayami, G, Clinicohistopathological correlation of skin biopsies in leprosy, Journal of Pathology Nepal, 3. 452-458. 2013.

[21] Vargas-Ocampo, Fransisco, Analysis of 6000 skin biopsies of the national Leprosy Control Programme in Mexico, Int J Lepr Other Mycobact Dis., 59. 28-35. 2004.

[22] Thakkar, S., Patel, S.V, Clinical profile of leprosy patients: A prospective study, Indian J Dermatol. 59. 158-162. 2014.

[23] Cree, I.A., Smith, W.C., Beck, J.S, A quantitative study of relationship between systemic and histological parameters in immunity in individual leprosy patients, Int J Lepr other Mycobact Dis, 58. 347-352. 1990.

[24] Moorthy, B.N., Kumar, P., Chatura, K.R., Chanderasekhar, H.R., Basavaraja, P.K, Histopathological correlation of skin biopsies in leprosy, Indian J Dermatol Ven Leprol, 67. 299-301. 2001.

[25] Bhatia, A.S., Katoch, K., Narayanan, B.R., Ramu, G., Mukherjee, A. et al., Clinical and histopathological correlation in the classification of leprosy, Int J Lepr, 61. 433-438. 1993.

[26] Bijjaragi, S., Kulkarni, V., Suresh, K.K., Chatura, K.R., Kumar, P, Correlation of clinical and histopathological classification of leprosy in post elimination era, Indian J Lepr, 84. 271-275. 2012.

[27] Mathur, M.C., Ghimire, R.B.K., Shrestha, P., Kedia, S.K, Clinicohistopathological correlation in leprosy. Kathmandu Univ. Med. J, 36(4). 249-252. 2011.

[28] Chacko, C.J.G, Role of histopathology in early diagnosis of leprosy, Indian J Lepr, 65. 23-27. 1993.

Pie Diagram - A

\section{Clinical presentations of various types of Leprosy}

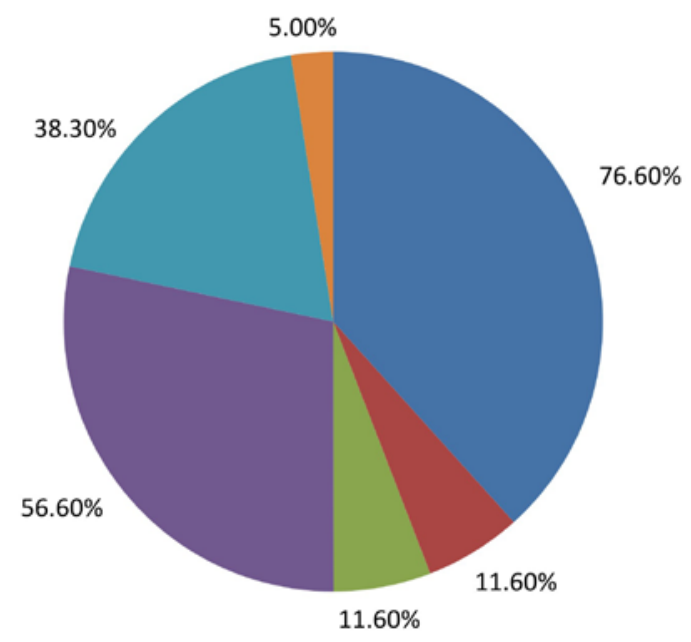

Hypo-pigmented patches

Erythematous plaques/ papules/ nodule

Combined

Anesthesia

Tropic ulcers

Nerve thickening 
Pie Diagram - B

\section{Clinical diagnosis of Leprosy}

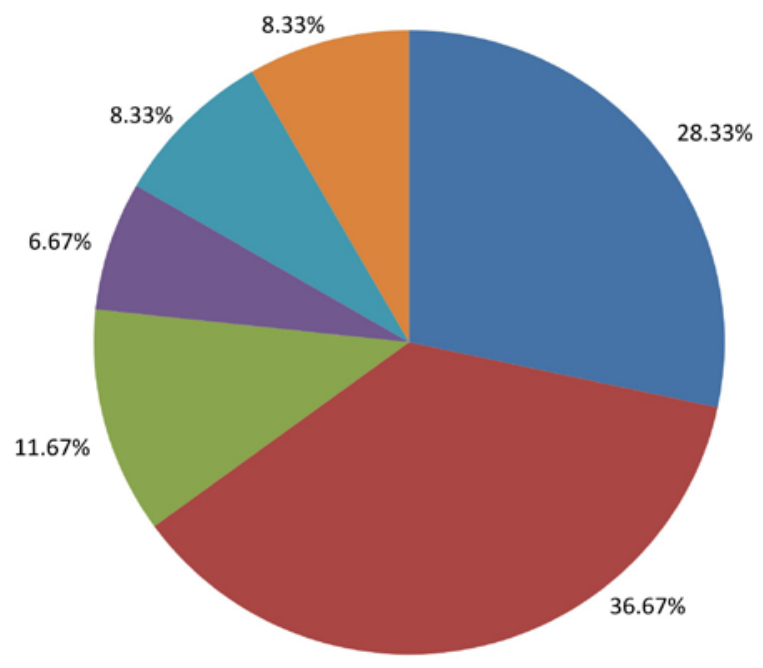

TT

BT

BB

BL

LL

IIL 